\title{
ANDALE Pittsburgh: results of a promotora- led, home-based intervention to promote a healthy weight in Latino preschool children
}

\author{
Sharon E. Taverno Ross ${ }^{1 *}$ (D), Bethany Barone Gibbs ${ }^{1}$, Patricia I. Documet ${ }^{2}$ and Russell R. Pate ${ }^{3}$
}

\begin{abstract}
Background: Latino preschool children have higher rates of obesity than preschool children from other racial/ ethnic groups; however, few effective, culturally appropriate interventions exist targeting this group. The purpose of this study was to test the feasibility of a 10-week, promotora-mediated, home-based intervention to promote a healthy weight in Latino preschool children.

Methods: Trained promotoras (community health workers) delivered 10, 90-min weekly interactive and tailored sessions to Latino families living in Allegheny County. Participants were recruited through promotoras' own social networks and community gatherings, flyers, and word of mouth. Primary outcome measures included child body mass index (BMI) z-score and percentile. Secondary outcome measures included child objectively measured physical activity and dietary intake, and the home social and physical environment (e.g., parent health behaviors, parent selfefficacy, parental support, physical activity equipment in the home). The final analysis sample included 49 of 51 participants who completed both baseline and follow-up assessments.
\end{abstract}

Results: Participants included mothers ( $33.5 \pm 6.1$ years old) and their preschool-aged children who were primarily 1st generation immigrants from Mexico (65\%). The primary analyses of BMI percentile and z-score showed no change post-intervention. However, there was a significant decrease in child BMI percentile for overweight and obese children from baseline to follow-up $(p<.05)$. We also saw significant pre/post increases in child daily fruit and vegetable intake, and parent moderate-to-vigorous physical activity, fruit and vegetable servings per day, and self-efficacy; and significant decreases in child saturated fat and added-sugar intake, and child and parent screen time ( $p$ 's <.05).

Conclusions: Despite the short duration of the intervention and follow-up, this pilot study showed promising effects of a promotora-mediated intervention to promote a healthy weight in Latino preschool children.

Keywords: Hispanic/Latino, Childhood obesity, Preschool, Community health worker, Intervention

\section{Background}

Children of immigrants are the fastest growing segment of the U.S. child population, the majority of which are of Asian or Latino origin [1, 2]. Approximately $16.7 \%$ of Latino preschool children are considered obese compared with $3.5 \%$ of non-Latino white, $11.3 \%$ non-Latino black, and 3.4\% of non-Latino Asian children [3]. This is troubling considering obesity tracks into adulthood and

\footnotetext{
*Correspondence: seross@pitt.edu

'Department of Health and Physical Activity, University of Pittsburgh, 32 Oak

Hill Court, Pittsburgh, PA 15261, USA

Full list of author information is available at the end of the article
}

puts children and adults at risk for a host of other comorbidities [4-6].

As the U.S. Latino population continues to increase, the public health need for effective, culturally-appropriate obesity interventions for Latino children escalates.

To date, few effective healthy lifestyle interventions exist that target Latino preschool children [7, 8]. There is a particular need for interventions that are inclusive of the entire family unit and include a culturally-sensitive approach. Promotoras (i.e., peer health educators who are trusted individuals from the community and share common characteristics with 
the priority population) [9-11] have been effective in increasing knowledge and promoting behavior changes in Latino populations [12]. Promotoras can serve as role models and provide social support to families, empowering them to identify their own needs and implement their own solutions [13]. To our knowledge, only two previous promotora-mediated healthy lifestyle interventions have targeted young Latino children and their parents [14, 15]; while the interventions were effective in changing child physical activity and dietary behaviors, they were not effective in reducing child weight status.

As such, the purpose of this pilot study was to test the feasibility of a 10-week, promotora-mediated, home-based intervention to promote a healthy weight in Latino preschool children. Using socioecological [16] and Social Cognitive Theory (SCT) [17] as a guide, we targeted changes in the home social (e.g., parental support and self-efficacy) and physical environment (e.g., physical activity equipment, TV in bedroom) associated with improvements in child physical activity, nutrition, and child weight status.

\section{Methods \\ Design}

This pilot study followed a single-group pre/post intervention design.

\section{Participants}

ANDALE Pittsburgh (2015-2016) included Latino parents and their 2-5 year old children living in Allegheny county. ANDALE Pittsburgh stands for Actividad, Nutrición, y Diversión, Apoyando a los Latinos En Pittsburgh (translated as Physical activity, nutrition, and Fun, Supporting Latinos in Pittsburgh). Allegheny county can be described as an emerging Latino community, i.e., anarea with low $(<5 \%)$ yet growing concentrations of Latinos [18]. Latinos living in this community are scattered throughout the region with no concentration in a single neighborhood or area $[19,20]$, and face barriers to health care, legal, and social services [19, 21]. Promotoras recruited participants through their own social networks (e.g., schools, churches, neighborhood) as well as at community gatherings, flyers, and word of mouth. Study staff screened interested participants for eligibility on the phone or in-person. Eligibility included that the participating parent: (1) self-identifies as Hispanic/Latino,

(2) has at least one child between 2 and 5 years old, and (3) speaks Spanish or English. Participants were ineligible if the participating child had a condition that would invalidate the measure of physical activity (e.g., wheelchairbound), or the parent primarily spoke a language other than Spanish or English.

\section{Promotoras recruitment/training}

Nine promotoras (females $>18$ years, active in community, ability to read/write in Spanish) were recruited through several community-based organizations, preexisting community contacts, and word of mouth. Promotoras received $25 \mathrm{~h}$ of training delivered by the Project Coordinator using a train-the-trainer model and the intervention curriculum finalized after a year-long developmental phase (described below). Specifically, training topics included promotora core roles, and skills-, health-, and research-based knowledge, as well as orientation to and role play with the intervention curriculum. Additional details of the intervention development and intervention description for ANDALE Pittsburgh have been published previously and can be found elsewhere [22].

\section{Intervention description}

This study was guided by a socioecological framework [16] and the SCT [17]. It was developed over a year-long process of conducting formative research with parents and key stakeholders in the community, as well as input from a community coalition and two research advisory boards. The intervention focused on improving dietary intake, decreasing sedentary behavior, and increasing physical activity using the 5,2,1,0 message (5 or more servings of fruits and vegetables, $2 \mathrm{~h}$ or less of recreational screen time, $1 \mathrm{~h}$ or more of physical activity, and 0 sugary drinks and more water) [23]. Promotoras delivered the home-based, face-to-face intervention to families over 10, 90-min weekly sessions that included education (i.e., session content related to the topic), practice (i.e., hands-on activities and role play), and action (i.e., goal setting and problem solving). Select intervention topics included a healthy lifestyle (i.e., diet and physical activity), reducing sedentary time, healthy eating for the entire family, and community nutrition and physical activity resources. Behavior modification constructs and strategies (e.g., goal setting, problem solving, social support), along with building of self-efficacy through healthy recipe preparation and physical activity breaks, were included. Additional details of the intervention development and intervention description can be found elsewhere [22].

\section{Data collection}

Data on child physical activity were collected via accelerometry; measures of child diet and the home social and physical environment were assessed via parent survey. A trained bilingual data collector visited participating families' homes with the promotora to get informed consent and deliver the accelerometer for the child to wear 7-10 days before Session \#1. Parents received detailed verbal and written instructions on how and when children should wear the accelerometers. The data 
collector completed the survey and anthropometric measures during the first and last home visits (\#1 and \#10). At Session \#10, the data collector also distributed the accelerometers for the children to wear during the following 7 days, and picked them up upon completion of the study. The Institutional Review Board at the University of Pittsburgh approved all study protocols.

\section{Outcomes}

For the current study, the primary outcomes included child BMI z-score and percentile. Secondary outcomes included child physical activity and diet, and the home social and physical environment (e.g., parent health behaviors, parent self-efficacy, parental support, physical activity equipment in the home).

\section{Measures}

\section{Anthropometry and weight status}

Parent and child height and weight were measured in light clothing and without shoes using a Seca model 213 mobile stadiometer and Seca model 869 digital scale. Body mass index (BMI) was calculated using the standard equation (body weight $[\mathrm{kg}] /$ height $[\mathrm{m}]^{2}$ ), and children were classified as normal weight (BMI percentile $<85$ ) or overweigh/ obese (BMI percentile $\geq 85$ ) based on Centers for Disease Control (CDC) growth charts [24].

\section{Physical activity}

Child physical activity was measured by ActiGraph GT3X (Pensacola, FL) accelerometers during a 7-day period. Children wore the monitors on an elastic belt on their right hip. Parents received instructions to remove the monitor only during sleep or water-related activities (e.g., bathing, swimming). Data was collected and stored in 15-s intervals to capture the sporadic activity patterns that are typical of young children. Data were reduced using ActiLife version 6 software with nonwear time defined as $60 \mathrm{~min}$ of 0 counts and activity intensity cutpoints developed for preschool-aged children [25, 26]. Accelerometry data was considered valid if participants had $\geq 8$ h of wear time on $\geq 3$ days at both baseline and follow-up $(n=22)$ [27]. For each participant, physical activity $(\mathrm{min} / \mathrm{h})$ and counts (per $\mathrm{min}$ ) were averaged over accelerometer wear time.

Parent physical activity was measured via self-report using three items adapted from a validated survey [28] and translated into Spanish. To estimate screen time, parents were also asked, on an average day, how many hours they spent watching TV, DVDs, or videos. Parents also reported how much time their child spent watching TV, playing or working on the internet/computer, and playing video games, per day.

\section{Diet}

Child dietary intake was assessed via English or Spanishlanguage versions of the validated Block Food Screener for Kids 2007 (NutritionQuest, Berkeley, CA) [29]. Parents completed this $15-20 \mathrm{~min}$ screener to assess children's dietary intake from the past week. A version of this screener has been used previously with Latino children [30]. Data were processed to estimate child's intake of whole/processed fruit (includes apples, applesauce, and other fruit; grams per day), vegetables (without potatoes; cups per day), whole grains (ounces per day), saturated fat (grams per day), added sugar and syrup (teaspoons per day), and sugar-sweetened beverages (calories per day).

\section{Home environment}

To assess the social and physical home environment related to diet and physical activity, parents completed a survey adapted from several sources and translated into Spanish. Physical activity items included physical activity resources and media availability [31], parent physical activity self-efficacy [32], modeling behaviors [33], and support for child physical activity [34]. Diet items included meal and feeding behaviors [35, 36] and support for child healthy eating [37]. Parenting strategies related to children's diet and physical activity were also assessed [38].

\section{Demographics}

Demographic variables were assessed via parent report at baseline and included information on parent and child age and gender, country of origin, parent marital status, employment status, highest education in household, and household income. Acculturation was measured using the Brief Acculturation Scale for Hispanics; the average of four questions about preferred language in different contexts was calculated and ranged from 0 (only Spanish, low acculturation) to 1 (only English, high acculturation) [39].

\section{Sample size calculations}

Sample size and power calculations for the intervention were based on repeated measures ANOVA with pre- to post-intervention change in BMI z-score as the primary outcome. We used GPower 3 software for all calculations. Based on data from a previous child obesity intervention with 2-4-year-old Latino children (mean decrease in BMI $\mathrm{Z}$-score of $.20, \mathrm{SE}=0.80$ ) [40], we expected that, on average, children participating in the intervention will slightly decrease their BMI z-score. We anticipated an effect size of .15 to .20 , with correlations between .60 to .80 . With 50 parent-child dyads, we had $65 \%$ to $90 \%$ power using a two-sided t-test and 5\% significance level. 


\section{Statistical analyses}

All data analyses were performed using Stata version 14 (College Station, TX). Descriptive statistics for baseline sociodemographic characteristics are summarized as either means and standard deviations or percentages and sample size. Changes from pre- to post-intervention were tested for statistical significant using paired $t$ tests or nonparametric Wilcoxon signed-rank tests for categorical, ordinal, or non-normally distributed data. Changes in child anthropometric measures were repeated after stratification by BMI percentile $(<85$ th, $\geq 85$ th). Statistical significance was set at $p<0.05$.

\section{Results}

Of 51 parent-child dyads enrolled in the home-based intervention ANDALE Pittsburgh (2015-2016), 49 (96\%) completed the intervention and assessments, and were included in analyses. Table 1 reports sociodemographic characteristics of the participants. The majority of the children were male (59.2\%; average age $3.9 \pm 1.3$ ), and all of the parents who completed baseline and follow-up assessments were mothers (100\%; average age $33.5 \pm$ 6.1 years). The majority of mothers were from Mexico (65\%) with low acculturation $(0.14 \pm 0.17)$, and $67.3 \%$ of the sample had lived in the U.S. for 6 or more years; $98 \%$ of the mothers were married and $71 \%$ reported being stayat-home caregivers. The highest household education level was almost equally split between high school or less (48\%) or more than high school (52\%). Forty-seven percent of families reported an annual household income of $\$ 34,999$ or less, $20 \%$ reported above $\$ 35,000$, and $33 \%$ didn't know/refused. Approximately $53 \%$ of children were categorized as normal weight, $18 \%$ were categorized as overweight, and $29 \%$ were categorized as obese.

Table 2 includes anthropometric variables at baseline, follow-up and change scores for children, overall and among children that had normal ( $<85$ th percentile, $n=26)$ or overweight/obese ( $\geq 85$ th percentile, $n=23$ ) BMI. Overall or within strata, child weight $(\mathrm{kg})$ increased significantly from baseline to follow-up. There were no other significant changes in child BMI z-score, BMI percentile, or waist circumference in the total sample. Noteworthy, however, was a significant decrease in BMI percentile among children who were overweight at the beginning of the intervention $(-1 \%, p=0.013)$. Also, there was a significant change in the distribution of normal vs. overweight/obese across follow-up (Fisher's exact test, $p<$ 0.001 ), with 1 of 26 normal weight children transitioning to overweight/obese and 5 of 23 overweight/obese children transitioning to normal weight.

Table 3 includes child dietary intake, physical activity, and screen time variables at baseline, follow-up, and change scores. There was a significant increase in daily intake of both fruit $(+4.43 \pm 1.26 \mathrm{~g}$ per day, $p=0.001)$
Table 1 Sociodemographic characteristics (\% [n], or $M \pm S D$ ) of participants $(n=49)$ in the ANDALE Pittsburgh home-based intervention

\begin{tabular}{|c|c|}
\hline \multicolumn{2}{|l|}{ Characteristic } \\
\hline Child gender, \% female & $40.8 \%(20)$ \\
\hline Child Age, years & $3.9 \pm 1.3$ \\
\hline Parent gender, \% female & $100 \%,(49)$ \\
\hline Parent Age & $33.5 \pm 6.1$ \\
\hline \multicolumn{2}{|l|}{ Country of Origin } \\
\hline Mexican & $32(65 \%)$ \\
\hline Guatemalan & $4(8 \%)$ \\
\hline Columbian & $4(8 \%)$ \\
\hline Venezuelan & $4(8 \%)$ \\
\hline Other & $5(10 \%)$ \\
\hline \multicolumn{2}{|l|}{ Marital Status } \\
\hline Married or in a committed relationship & $48(98 \%)$ \\
\hline Divorced/separated & $1(2 \%)$ \\
\hline \multicolumn{2}{|l|}{ Employment (parent) } \\
\hline Working full time & $4(8 \%)$ \\
\hline Working part time & $8(16 \%)$ \\
\hline Stay at home caregiver & $35(71 \%)$ \\
\hline Currently unemployed, but seeking work & $2(4 \%)$ \\
\hline \multicolumn{2}{|l|}{ Education (highest in household) } \\
\hline Did not finish high school & $7(14 \%)$ \\
\hline Finished high school or GED & $16(33 \%)$ \\
\hline Some college or training after high school & $10(20 \%)$ \\
\hline Finished college & $10(20 \%)$ \\
\hline Advanced degree & $6(12 \%)$ \\
\hline \multicolumn{2}{|l|}{ Income } \\
\hline Less than $\$ 20,000$ & $17(35 \%)$ \\
\hline$\$ 20,000-34,999$ & $6(12 \%)$ \\
\hline$\$ 35,000-49,999$ & $4(8 \%)$ \\
\hline$\$ 50,000-74,999$ & $2(4 \%)$ \\
\hline$\$ 75,000-99,999$ & $1(2 \%)$ \\
\hline$\$ 100,00$ or more & $3(6 \%)$ \\
\hline Don't know/refused & $16(33 \%)$ \\
\hline \multicolumn{2}{|l|}{ Acculturation } \\
\hline Low (0-0.25) & $42(86 \%)$ \\
\hline Moderate $(0.26-0.50)$ & $5(10 \%)$ \\
\hline High (0.51-1) & $2(4 \%)$ \\
\hline
\end{tabular}

and vegetables $(+0.14 \pm 0.06$ cups per day, $p=0.034)$. Children also had significant decreases in saturated fat $(-3.0 \pm 0.6 \mathrm{~g}$ per day, $p<0.001)$, added sugar/syrup $(-1.63 \pm 3.03$ teaspoons per day, $\mathrm{p}<0.001)$, and calories from sugar-sweetened beverages $(-7.8 \pm 26.0 \mathrm{kcals}$ per day, $p=0.040)$. Of children meeting minimum weartime requirements for the objective activity assessment, 
Table 2 Anthropometric measures at baseline, follow-up, and change scores (mean \pm SD or median [25th, 75th percentile]), among children participating in ANDALE Pittsburgh by weight status [overall $(n=49)$, and in children with body mass index percentile $<85$ th $(n=26)$ or $\geq 85$ th $(n=23)]$

\begin{tabular}{|c|c|c|c|c|c|}
\hline & & Baseline & Follow-up & Change Score & $p$-value \\
\hline \multirow[t]{3}{*}{ Child weight, kg } & Overall & $18.5 \pm 5.3$ & $19.0 \pm 5.3$ & $0.5 \pm 0.8$ & 0.002 \\
\hline & $<85$ th percentile & $16.7 \pm 3.1$ & $17.1 \pm 3.2$ & $0.4 \pm 0.6$ & 0.003 \\
\hline & $\geq 85$ th percentile & $20.6 \pm 6.5$ & $21.1 \pm 6.4$ & $0.5 \pm 1.0$ & 0.013 \\
\hline \multirow[t]{3}{*}{ Child BMI z-score ${ }^{a}$} & Overall & $0.96 \pm 1.29$ & $0.91 \pm 1.35$ & $-0.05 \pm 0.44$ & 0.437 \\
\hline & $<85$ th percentile & $0.08 \pm 0.06$ & $0.02 \pm 0.08$ & $-0.05 \pm 0.04$ & 0.535 \\
\hline & $\geq 85$ th percentile & $2.00 \pm 1.06$ & $1.96 \pm 1.11$ & $-0.05 \pm 0.47$ & 0.643 \\
\hline \multirow[t]{3}{*}{ Child BMI percentile ${ }^{a}$} & Overall & $83[43,96]$ & $82[50,94]$ & $0[-7,2]$ & 0.430 \\
\hline & $<85$ th percentile & $45[31,74]$ & $53[26,77]$ & $1.5[-10,10]$ & 0.557 \\
\hline & $\geq 85$ th percentile & $96[90,99]$ & $94[87,99]$ & $-1[-3,0]$ & 0.013 \\
\hline \multirow[t]{3}{*}{ Child waist circumference, $\mathrm{cm}$} & Overall & $56.0 \pm 10.5$ & $55.7 \pm 7.5$ & $-0.3 \pm 7.4$ & 0.797 \\
\hline & $<85$ th percentile & $52.7 \pm 10.3$ & $52.6 \pm 4.2$ & $0.1 \pm 9.9$ & 0.969 \\
\hline & 285th percentile & $59.6 \pm 9.7$ & $59.2 \pm 8.9$ & $-0.5 \pm 2.7$ & 0.398 \\
\hline
\end{tabular}

NOTE: Data were compared using paired $t$ tests or nonparametric Wilcoxon signed-rank tests; Baseline vs. follow-up data compared using paired $t$ test or a nonparametric sign test;

$B M I$ body mass index;

${ }^{a}$ One child's BMI was too high to calculate a z-score or percentile at baseline or follow-up;

$p$-values $<0.05$ were bolded to indicate statistical significance

average wear time was $12.2 \pm 1.6 \mathrm{~h}$ on $5.0 \pm 1.2$ days. There were no statistically significant changes from baseline to follow-up in any of the physical activity variables (accelerometry) or average counts per minute. However, there was a statistically significant decrease in parent- reported minutes per day of child screen time (60 $[35,120]$ vs. $60[32,90] ; p=0.02)$.

Figure 1 and Additional file 1: Table S1 include dietary intake, physical activity, screen time, and anthropometric variables for parents at baseline, follow-up, and change

Table 3 Diet, physical activity, and screen time at baseline, follow-up, and change scores $(\mathrm{M} \pm \mathrm{SD})$ among children participating in ANDALE Pittsburgh intervention

\begin{tabular}{|c|c|c|c|c|}
\hline & Baseline & Follow-up & Change Score & $p$-value \\
\hline \multicolumn{5}{|l|}{ Dietary Intake $(n=49)$} \\
\hline Fruit, grams per day & $19.29 \pm 1.27$ & $23.71 \pm 1.39$ & $4.43 \pm 1.26$ & 0.001 \\
\hline Vegetables (no potatoes), cups per day & $0.49 \pm 0.42$ & $0.63 \pm 0.60$ & $0.14 \pm 0.06$ & 0.034 \\
\hline Whole Grains, oz. per day & $0.72 \pm 0.64$ & $0.74 \pm 0.87$ & $0.02 \pm 0.65$ & 0.790 \\
\hline Saturated Fat, grams per day & $15.2 \pm 7.3$ & $12.2 \pm 7.4$ & $-3.0 \pm 0.6$ & $<0.001$ \\
\hline Sugar/syrup added to foods/beverages, tsp per day & $5.06 \pm 3.58$ & $3.43 \pm 2.21$ & $-1.63 \pm 3.03$ & $<0.001$ \\
\hline Sugar-Sweetened Beverages, kcals per day & $15.5 \pm 26$ & $7.6 \pm 12.1$ & $-7.8 \pm 26.0$ & 0.040 \\
\hline \multicolumn{5}{|l|}{ Objectively-measured Physical Activity $(n=22)$} \\
\hline Sedentary behavior, $\mathrm{min} / \mathrm{h}$ & $34.7 \pm 3.4$ & $34.8 \pm 4.3$ & $0.1 \pm 0.8$ & 0.942 \\
\hline Very Light, $\mathrm{min} / \mathrm{h}$ & $12.3 \pm 1.7$ & $12.2 \pm 2.0$ & $-0.2 \pm 1.2$ & 0.531 \\
\hline Light Activity, min/h & $6.5 \pm 1.1$ & $6.8 \pm 1.3$ & $0.2 \pm 1.0$ & 0.308 \\
\hline Moderate Activity, min/h & $4.7 \pm 1.3$ & $4.8 \pm 1.6$ & $0.1 \pm 0.3$ & 0.770 \\
\hline Vigorous Activity, min/h & $1.7 \pm 1.1$ & $1.4 \pm 1.1$ & $-0.2 \pm 0.8$ & 0.223 \\
\hline Total Activity, min/h & $25.2 \pm 3.4$ & $25.2 \pm 3.4$ & $-0.1 \pm 3.5$ & 0.942 \\
\hline Average Counts per Minute & $543 \pm 145$ & $532 \pm 35$ & $-12 \pm 133$ & 0.681 \\
\hline \multicolumn{5}{|l|}{ Screen Time $(n=49)$} \\
\hline Screen time, minutes/day & $60[35,120]$ & $60[32,90]$ & $0[-60,0]$ & 0.020 \\
\hline
\end{tabular}

Data are reported as mean \pm SD or $\mathrm{n}(\%)$ across ordinal categories. Data were compared using paired $t$ tests or nonparametric Wilcoxon signed-rank tests $p$-values $<0.05$ were bolded to indicate statistical significance 


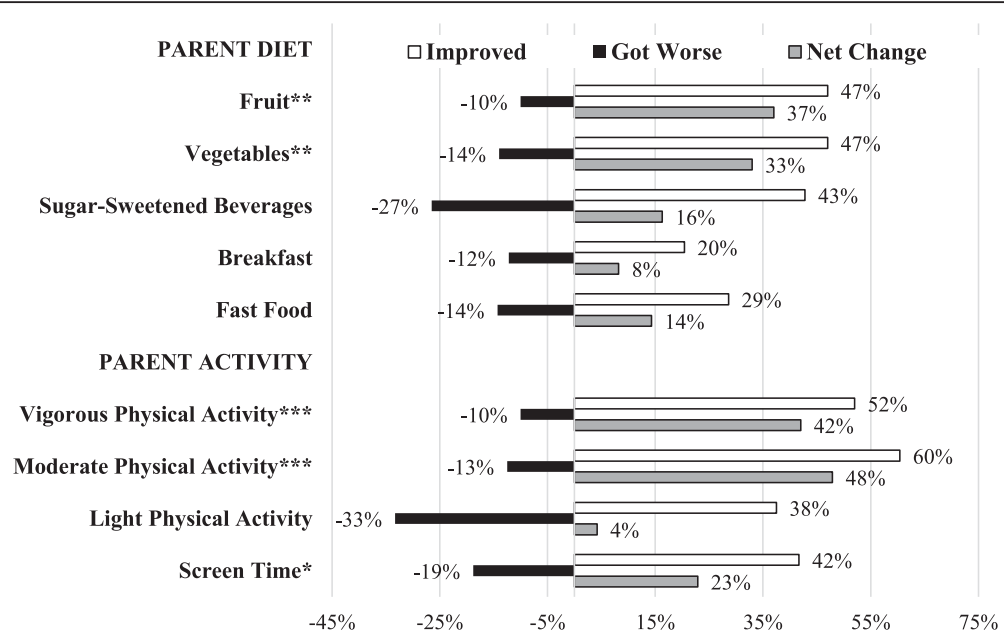

Fig. 1 Parent diet, physical activity, and screen time outcomes in the ANDALE Pittsburgh intervention $(n=49)$. Parents answered semiquantitative questions at baseline and follow-up. Relative frequency of improving (white bar), worsening (black bar), and the net change (gray bar) are presented. ${ }^{*} p<0.05 ;{ }^{* *} p<0.01 ;{ }^{* * *} p<0.001$ for significant improvement over time by the Wilcoxon test

scores from semi-quantitative questionnaires. In Fig. 1, the proportion of parents improving, worsening, and the net improvement in dietary and activity behaviors are displayed. Parents significantly improved (net change indicated by gray bars) intake of fruits $(p=0.001)$ and vegetables $(p=0.002)$, engagement in vigorous physical activity $(p<0.001)$ and moderate physical activity $(p<0.001)$, and screen time $(p=0.016)$. No changes were observed in anthropometric measures (Additional file 1: Table S1).

Additional file 2: Table S2 includes features of the home social and physical environment at baseline, follow-up, and change scores, for parent-child dyads participating in ANDALE Pittsburgh $(n=49)$. In general, we did not detect statistically significant differences in measures of the social and physical home environment to promote physical activity and nutrition in the children. However, parent reported self-efficacy to overcome barriers to physical activity significantly increased from baseline to follow-up $(p=0.024)$.

\section{Discussion}

ANDALE Pittsburgh is one of the first healthy lifestyle interventions that was delivered by promotoras and targeted Latino preschool-aged children and their families. Despite the short duration of intervention and follow up, we saw significant pre/post improvements in both child and parent self-reported dietary intake and screen time, and parent physical activity. These findings suggest that a promotora-mediated intervention with Latino preschool children living in an emerging Latino community may be effective in improving both child and parent behaviors associated with excessive weight gain (i.e., physical activity, dietary intake, sedentary behavior).
Previous healthy lifestyle programs with promotoras targeting young Latino children have had some success in improving physical activity and nutrition. For example, one previous 3-year intervention, Aventuras Para Niños study, targeted young Latino children (K-2nd grade) and their parents [14]. In the school/community-level arm of the intervention of this study, parents reported increased child physical activity, reduced child frequency of watching TV when getting ready for school, and increased child's daily consumption of fruits and vegetables. Conversely, similar results were not observed in the intervention arm delivered in homes by promotoras. In another 9-month intervention study by Bender et al. [15] targeting low-income Mexican American mothers and their 3-5 year old children, the authors found significant decreases in child sugar-sweetened beverage consumption, and significant increases in child water consumption and maternal step counts measured by pedometers. However, in both of these studies, they did not see expected improvements in child weight status.

We saw a significant reduction in BMI percentile for those children who were overweight or obese at baseline. These results are similar to previous studies with young Latino children where the strongest intervention effect was seen in the obese children [40-42], while others saw no effect $[14,15,43,44]$. In general, results have been mixed regarding intervention effects on BMI of preschool-aged children $[7,8,45,46]$. While we would not necessarily expect a decrease in BMI for those growing and normal weight preschool children, it is unclear whether the lack of change over the intervention period (i.e., maintenance of BMI z-score or percentile) can be defined as success without the comparison of a control group. For example, it's possible we would have seen an increase in BMI z-score or percentile over the intervention period in the control 
group. As such, the intervention should be evaluated on a larger scale, with a longer intervention and follow-up period, using an experimental design with a control group, as well as adequate sample sizes across the BMI categories (normal, overweight, obese).

A recent decade review of cross-sectional and longitudinal studies examining home environmental influences on obesity in Latino children found that key factors included: a) parental influences (e.g., feeding practices, modeling), b) screen time behaviors and rules, c) child and parent physical activity/sedentary behavior, d) socioeconomic status/food security, and e) sleep deprivation [47]. According to our theoretical framework, we hypothesized that changes in child behaviors and weight status would occur through changes in the home social and physical environment and modeling of healthy parent behaviors. While we saw significant improvements in parent physical activity and nutrition behaviors, the only significant change related to the home social and physical environment was parent self-efficacy to overcome physical activity barriers. Previous studies have had some success in improving Latino children's home social and physical environment related to physical activity and nutrition $[14,48,49]$. However, much remains to be understood about the most important early risk and protective factors for Latino child obesity, and how best to tailor intervention approaches to Latino families and the home-environment.

There is little known about Latinos living in these emerging Latino communities, even less about determinants of obesity and potentially effective intervention approaches. A major strength of this study is that it was one of the first to examine the feasibility of a promotora-led, healthy lifestyle intervention in Latino preschool children living in an emerging community. Further, our sample of parents and children was representative of the racial/ethnic and socioeconomic background of the Latino population living in this community. Another strength is the excellent retention of the sample across the 10-week intervention. However, the study is not without limitations. Given the small sample size of the pilot study, we were not adequately powered to examine differences in these results by gender, BMI, or physical activity level. Further, while child physical activity was measured objectively by accelerometry, the criteria for adequate wear time limited number of children with complete data to only $n=22$, which may have prevented us from seeing any meaningful pre/post differences.

\section{Conclusions}

In conclusion, there are clear disparities in child obesity for preschool-aged Latino children, and there is a lack of knowledge surrounding effective intervention approaches to promote a healthy weight this population. The present study suggests a promotora intervention is associated with self-reported changes in important behaviors linked to excessive weight gain. The results of this pilot study are promising and suggest the need to examine the intervention in a longer and larger, experimental study with a control group to confirm and extend our findings. If successful, this research could provide a potential model to help to address and prevent obesity and promote a healthy weight in Latino families with preschool children, a highly significant and growing public health problem.

\section{Additional files}

Additional file 1: Table S1. Parent weight, diet, physical activity, and screen time outcomes in the ANDALE Pittsburgh intervention $(n=49)$. Pre/post and change scores for parent-level outcome variables assessed in the intervention. (DOCX $16 \mathrm{~kb})$

Additional file 2: Table S2. Home environment at baseline and followup, and change scores, in the ANDALE Pittsburgh intervention $(n=49)$. Pre/post and change scores for home-level outcome variables assessed in the intervention. (DOCX $19 \mathrm{~kb}$ )

\section{Abbreviations}

BMI: Body mass index; CDC: Centers for disease control; SCT: Social cognitive theory

\section{Acknowledgements}

The authors would like to thank the numerous individuals, both academic and community-based, who provided valuable feedback on the intervention protocol.

\section{Funding}

This work was supported by a grant from the National Heart, Lung, and Blood Institute at the National Institutes of Health $(\mathrm{NIH} / \mathrm{NHLBI}$

5R21HL119395-03). The contents of this publication do not necessarily reflect the views or policies of the $\mathrm{NIH}$, nor does mention of organization imply endorsement from the US government.

\section{Availability of data and materials}

The datasets used and/or analysed during the current study are available from the corresponding author on reasonable request.

\section{Authors' contributions}

SR was the PI on the study and along with RP conceptualized and designed the study. SR and PD contributed to acquisition of the data. BG conducted the data analysis. All authors contributed to the interpretation of the data, drafting of the manuscript, and have read an approved the final manuscript.

\section{Ethics approval and consent to participate}

The Institutional Review Board at the University of Pittsburgh approved all study protocols. Written, informed parental consent was obtained for children participating in this study, and that written, informed consent was obtained from all participants over the age of 18 years old.

\section{Consent for publication}

Not applicable.

Competing interests

The authors declare that they have no competing interests.

\section{Publisher's Note}

Springer Nature remains neutral with regard to jurisdictional claims in published maps and institutional affiliations. 


\section{Author details}

Department of Health and Physical Activity, University of Pittsburgh, 32 Oak Hill Court, Pittsburgh, PA 15261, USA. ${ }^{2}$ Department of Behavioral and Community Health Sciences, University of Pittsburgh, 130 De Soto Street, Pittsburgh, PA 15261, USA. ${ }^{3}$ Department of Exercise Science, University of South Carolina, 921 Assembly Street, Columbia, SC 29208, USA.

\section{Received: 20 July 2017 Accepted: 7 March 2018}

\section{Published online: 16 March 2018}

\section{References}

1. Woods T, Hanson D. Demographic trends of children of immigrants. In: Immigrant Children. Washington, DC: Urban Institute; 2016. p. 1-8.

2. Hernandez DJ, Denton NA, Macartney SE. Children in immigrant families: looking to America's future. Social Policy Report. 2008;21:3-22.

3. Ogden C, Carroll M, Fryar C, Flegal K. Prevalence of obesity among adults and youth: United States, 2011-2014. NCHS data brief 2015(219):1-8.

4. Singh AS, Mulder C, Twisk JW, van Mechelen W, Chinapaw MJ. Tracking of childhood overweight into adulthood: a systematic review of the literature. Obes Rev. 2008;9(5):474-88.

5. McLeod DL, Buscemi J, Bohnert AM. Becoming American, becoming obese? A systematic review of acculturation and weight among Latino youth. Obes Rev. 2016;17(11):1040-9.

6. Reilly JJ, Kelly J. Long-term impact of overweight and obesity in childhood and adolescence on morbidity and premature mortality in adulthood: systematic review. Int J Obes. 2011;35(7):891-8.

7. Laws R, Campbell KJ, van der Pligt $P$, et al. The impact of interventions to prevent obesity or improve obesity related behaviours in children (0-5 years) from socioeconomically disadvantaged and/or indigenous families: A systematic review. BMC Public Health. 2014;14(1):1.

8. Tovar A, Renzaho AM, Guerrero AD, Mena N, Ayala GA. systematic review of obesity prevention intervention studies among immigrant populations in the US. Curr Obes Rep. 2014;3(2):206-22

9. Fisher EB, Coufal MM, Parada H, et al. Peer support in health care and prevention: Cultural, organizational, and dissemination issues. Annu Rev Public Health. 2014;35:363-83.

10. Ayala GX, Vaz L, Earp JA, Elder JP, Cherrington A. Outcome effectiveness of the lay health advisor model among Latinos in the United States: an examination by role. Health Educ Res. 2010;25(5):815-40.

11. Rhodes SD, Foley KL, Zometa CS, Bloom FR. Lay health advisor interventions among Hispanics/Latinos: a qualitative systematic review. Am J Prev Med. 2007;33(5):418-27.

12. Andrews $\mathrm{JO}$, Felton $\mathrm{G}$, Wewers $\mathrm{ME}$, Heath J. Use of community health workers in research with ethnic minority women. J Nurs Scholarsh. 2004; 36(4):358-65.

13. Witmer A, Seifer SD, Finocchio L, Leslie J, O'Neil EH. Community health workers: integral members of the health care work force. Am J Public Health. 1995;85(8_Pt_1):1055-8.

14. Crespo NC, Elder JP, Ayala GX, et al. Results of a multi-level intervention to prevent and control childhood obesity among Latino children: The Aventuras Para Niños Study. Ann Behav Med. 2012;43(1):84-100

15. Bender MS, Nader PR, Kennedy C, Gahagan S. A culturally appropriate intervention to improve health behaviors in Hispanic mother-child dyads. Child Obes. 2013:9:157-63.

16. Bronfenbrenner $U$, Bronfenbrenner $U$. The ecology of human development: Experiments by nature and design. Cambridge: MA; Harvard University Press; 2009.

17. Bandura A. Social foundations of thought and action: a social cognitive theory. Englewood Cliffs, NJ: Prentice-Hall, Inc; 1986.

18. Cunningham P, Banker M, Artiga S, Tolbert J. Health coverage and access to care for Hispanics in "new growth communities" and "major Hispanic centers". Washington, DC: Kaiser Commission on Medicaid and the Uninsured; 2006

19. Documet PI, Sharma RK. Latinos' health care access: financial and cultural barriers. J Immigr Health. 2004;6(1):5-13.

20. Macia L. Experiences of discrimination in an emerging Latina/o community. PoLAR: Political and Legal Anthropology Review. 2016:39(1):110-26.

21. Documet PI, Kamouyerou A, Pesantes A, et al. Participatory assessment of the health of Latino immigrant men in a community with a growing Latino population. J Immigr Minor Health. 2015;7:239-47.
22. Taverno Ross SE, Documet PI, Pate RR, Smith-Tapia I, Wisniewski LM, Gibbs BB. Study protocol for a home-based obesity prevention program in Latino preschool children. Translational journal of the American College of. Sports Med. 2017:2(14):85-91.

23. 5210 LET'S GO! 2016; http://www.letsgo.org/. Accessed 14 Mar 2018.

24. Kuczmarski RJ, Ogden CL, Grummer-Strawn LM, et al. CDC growth charts: United States. Adv Data. 2000;314:1-27.

25. Pate RR, Almeida MJ, Mclver KL, Pfeiffer KA, Dowda M. Validation and calibration of an accelerometer in preschool children. Obesity. 2006;14(11):2000-6.

26. Evenson KR, Catellier DJ, Gill K, Ondrak KS, McMurray RG. Calibration of two objective measures of physical activity for children. J Sports Sci. 2008;26(14): 1557-65.

27. Pate RR, Brown WH, Pfeiffer KA, et al. An intervention to increase physical activity in children: A randomized controlled trial with 4-year-olds in preschools. Am J Prev Med. 2016;51(1):12-22.

28. Neumark-Sztainer D, MacLehose R, Loth K, Fulkerson JA, Eisenberg ME, Berge J. What's for dinner? Types of food served at family dinner differ across parent and family characteristics. Public Health Nutr. 2014;17(1):145-55

29. Hunsberger M, O'Malley J, Block T, Norris JC. Relative validation of Block Kids Food Screener for dietary assessment in children and adolescents. Matern Child Nutr. 2015;11(2):260-70.

30. Davis JN, Ventura EE, Cook LT, Gyllenhammer LE, Gatto NM. LA Sprouts: a gardening, nutrition, and cooking intervention for Latino youth improves diet and reduces obesity. J Am Diet Assoc. 2011;111(8):1224-30.

31. Dennison BA, Erb TA, Jenkins PL. Television viewing and television in bedroom associated with overweight risk among low-income preschoo children. Pediatrics. 2002;109(6):1028-35.

32. Sallis JF, Pinski RB, Grossman RM, Patterson TL, Nader PR. The development of self-efficacy scales for healthrelated diet and exercise behaviors. Health Educ Res. 1988;3(3):283-92

33. Eaton DK, Kann L, Kinchen S, et al. Youth risk behavior surveillance-United States, 2009. MMWR Surveill Summ. 2010:59(5):1-142.

34. Sallis JF, Taylor WC, Dowda M, Freedson PS, Pate RR. Correlates of vigorous physical activity for children in grades 1 through 12: comparing parent-reported and objectively measured physical activity. Pediatr Exerc Sci. 2002;14(1):30.

35. Centers for Disease Control and Prevention. The National Youth Physical Activity and Nutrition Study. 2010; ftp://ftp.cdc.gov/pub/data/yrbs/nypans/ 2010nypans_questionnaire.pdf. Accessed 14 Mar 2018.

36. Centers for Disease Control and Prevention. Flexible Consumer Behavior Survey. National Health and Nutrition Examination Survey 2009-2010 2009; https://wnw. cdc.gov/nchs/data/nhanes/nhanes_09_10/fcbs_f.pdf. Accessed 14 Mar 2018.

37. Sallis JF, Grossman RM, Pinski RB, Patterson TL, Nader PR. The development of scales to measure social support for diet and exercise behaviors. Prev Med. 1987;16(6):825-36.

38. Larios SE, Ayala GX, Arredondo EM, et al. Development and validation of a scale to measure Latino parenting strategies related to children's obesigenic behaviors. The Parenting strategies for Eating and Activity Scale (PEAS). Appetite. 2009:52(1):166-72.

39. Mills SD, Malcarne VL, Fox RS, Sadler GR. Psychometric evaluation of the Brief Acculturation Scale for Hispanics. Hisp J Behav Sci. 2014;36(2):164-74

40. Slusser W, Frankel F, Robison K, Fischer H, Cumberland WG, Neumann C. Pediatric overweight prevention through a parent training program for $2-4$ year old Latino children. Child Obes. 2012:8(1):52-9.

41. Barkin SL, Gesell SB, Po'e EK, Escarfuller J, Tempesti T. Culturally tailored, family-centered, behavioral obesity intervention for Latino-American preschool-aged children. Pediatrics. 2012;130(3):445-56

42. Yin Z, Parra-Medina D, Cordova A, et al. Miranos! Look at us, we are healthy! An environmental approach to early childhood obesity prevention. Child Obes. 2012;8(5):429-39.

43. Davis SM, Myers OB, Cruz TH, et al. CHILE: Outcomes of a group randomized controlled trial of an intervention to prevent obesity in preschool Hispanic and American Indian children. Prev Med. 2016:89:162-8.

44. Fitzgibbon ML, Stolley MR, Schiffer L, et al. Family-based hip-hop to health: Outcome results. Obesity. 2013:21(2):274-83.

45. Peirson L, Fitzpatrick-Lewis D, Morrison K, et al. Prevention of overweight and obesity in children and youth: A systematic review and meta-analysis. CMAJ Open. 2015;3(1):E23-33.

46. Showell NN, Fawole O, Segal J, et al. A systematic review of home-based childhood obesity prevention studies. Pediatrics. 2013;132(1):e193-200. 
47. Ochoa A, Berge JM. Home environmental influences on childhood obesity in the Latino population: A decade review of literature. J Immigr Minor Health. 2017;19(2):430-47.

48. Keita AD, Risica PM, Drenner KL, Adams I, Gorham G, Gans KM. Feasibility and acceptability of an early childhood obesity prevention intervention: results from the Healthy Homes. Healthy Families pilot study J Obes. 2014;2014:378501.

49. Ayala GX, Elder JP, Campbell NR, et al. Longitudinal intervention effects on parenting of the Aventuras para Niños study. Am J Prev Med. 2010;38(2):154-62.

Submit your next manuscript to BioMed Central and we will help you at every step:

- We accept pre-submission inquiries

- Our selector tool helps you to find the most relevant journal

- We provide round the clock customer support

- Convenient online submission

- Thorough peer review

- Inclusion in PubMed and all major indexing services

- Maximum visibility for your research

Submit your manuscript at www.biomedcentral.com/submit 